Fine-grained Morphophonological Variation in Scottish Gaelic:

Evidence from the Linguistic Survey of Scotland

Anna Bosch, University of Kentucky (bosch@uky.edu)

James Scobbie, Queen Margaret University, Edinburgh (JScobbie@qmu.ac.uk)

THIS DRAFT (C) Anna Bosch and James M Scobbie 2008

The revised and corrected version should be consulted, published 2009 as:

\title{
15. Fine-grained morphophonological variation in Scottish Gaelic: Evidence from the Linguistic Survey of Scotland
}

In: Stanford, James N. and Dennis R. Preston (eds.), Variation in Indigenous Minority Languages. 2009. vii, 519 pp. (pp. 347-368)

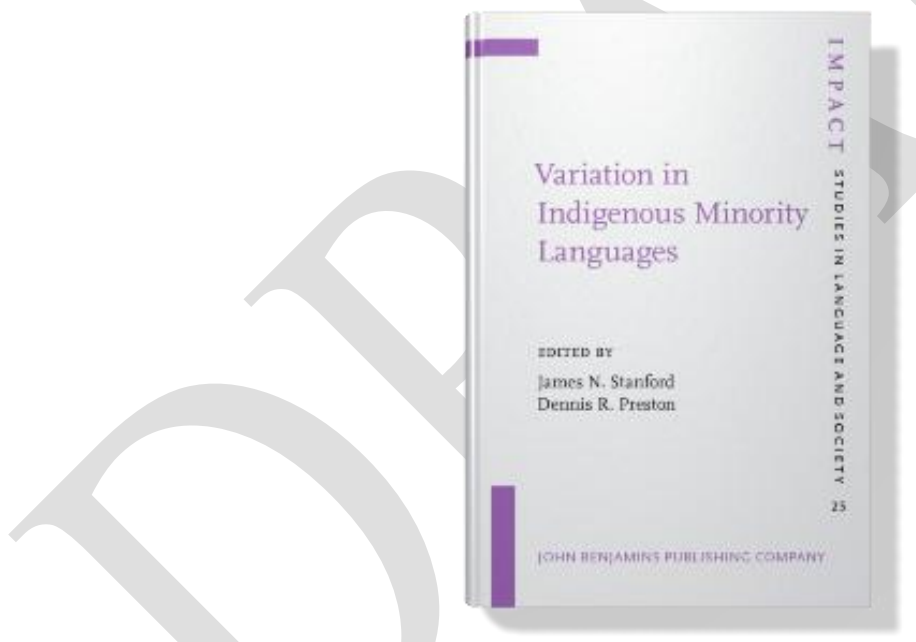

IMPACT: Studies in Language and Society 25

2009. vii, 519 pp.

Hardbound

9789027218643 / EUR 105.00 / USD 158.00

e-Book - Available from e-book platforms

9789027289780 / EUR 105.00 / USD 158.00 


\title{
Fine-grained Morphophonological Variation in Scottish Gaelic: Evidence from the Linguistic Survey of Scotland ${ }^{i}$
}

\author{
Anna Bosch, University of Kentucky (bosch@uky.edu) \\ James Scobbie, Queen Margaret University, Edinburgh (JScobbie@qmu.ac.uk)
}

\begin{abstract}
Descriptive accounts of Scottish Gaelic dialects (e.g. Borgstrøm 1937, Oftedal 1956, Ternes 1973) have noted significant regional variation in the surface description of nasal mutation; this paper brings previously unpublished data from archives of the Linguistic Survey of Scotland to bear on the full range of variation across Gaelic speaking Scotland. We employ data from the archives of the Linguistic Survey of Scotland to map out the actual range of variation in the nasal mutation; using Mapmaker software we focus on three graded parameters: voicing, aspiration, and nasalization. With this research we demonstrate the continuing value of "historical" data for the analysis of endangered and minority languages. As yet, no maps have been published based on this survey data.
\end{abstract}

\section{Introduction}

The international linguistic community generally recognizes the value and indeed the timeliness of continued research on endangered or minority languages; the increased grant funding available for fieldwork and other projects specifically focusing on endangered languages is one sign of the value we place on this work. We welcome a renewed focus on research encompassing all aspects of endangered languages, from descriptive work on phonology and syntax to variationist studies on social aspects of language use. However, research on any single endangered language often suffers from a very specific constraint: lack of data. This is a central part of what it means, after all, when we call a language "endangered", and one of the reasons additional fieldwork is highly prized. Ideally data collection and analysis work hand in hand (although we know in a practical sense this is not always how we work). Consequently, new data are often gathered to address a new theoretical question. But this should not lead us to conclude that extant data has little relevance or is unable to illuminate contemporary theoretical debates. In fact, it is worthwhile and important to stop collecting data and look back at what we have: what we can in fact learn from the data we now have at hand. Even if this data is limited, or constrained in some way, or available only in some far-from-ideal presentation, nonetheless we owe it to our field to examine exactly what we can learn from what we have. Part of our purpose in this article is to test the limits of what we can learn from data that is available, and yet imperfect—in this case, data on regional variation in Scottish Gaelic.

While the data we draw from are in a sense "historical", in a very real sense they provide the widest window for a snapshot of the geographical distribution of the phonological organization of Scottish Gaelic. The Linguistic Survey of Scotland, described in more detail in the following section, involved the efforts of more than 200 speakers of Gaelic, 
interviewed by eight or more fieldworkers over a period of nearly 15 years between 1949 and 1963 (that period extending to 46 years prior to eventual publication), as well as the dedication of numerous scholars and ad hoc advisors before the main part of the project was made available in published form. And yet very little analysis of this survey data has been completed (although see Ó Dochartaigh 1996 and Ó Maolalaigh 1999). To ignore this data would be to deny ourselves an immense storehouse of fascinating and detailed information on the complete range of Gaelic pronunciation in the mid-twentieth century. We argue here that linguists must look at imperfect data with an eye to exploiting what it $i$ able to tell us, especially in the case of endangered languages - it may be all we ever have.

\section{A. The Linguistic Survey of Scotland: Gaelic section}

During the late 1940s a project developed out of the combined interests of the Celtic, English Language, and Phonetics departments at Edinburgh University to produce a linguistic atlas of the Gaelic and English (Scots) dialects of Scotland; the project soon came to be known as the Linguistic Survey of Scotland (Gillies 1997 in Ó Dochartaigh 1994-7). The Gaelic and Scots sections of the project became separate endeavors shortly thereafter, with the Gaelic section directed by Kenneth H. Jackson, professor of Celtic at Edinburgh, aided by the additional phonetic expertise of David Abercrombie, professor of Phonetics. Eight fieldworkers, including Jackson himself, covered the geographic region of the Gaidhealtachd between 1949 and 1963; additional fieldwork continued in a sporadic fashion through the 1980s, and contributes to the archival holdings of the Survey. In 1994-7, the "phonetic record" of the transcribed questionnaires of the Survey of the Gaelic Dialects of Scotland (henceforth SGDS; Ó Dochartaigh 1994-7, ed.) was published as a five-volume series, presenting one volume of explanatory material and four volumes of the narrow phonetic transcriptions of 207 speakers responding to a fortyeight-page word-list questionnaire. Interviews included in this published record took place mainly prior to 1963 ; one additional point (St. Kilda speaker, point 16) is included from fieldwork by Eric Hamp in the 1980s. In many cases, some of the very last Gaelic speakers in a particular region were interviewed, and we thus have transcribed material of dialects that are now practically extinct. Naturally, the historic quality of these records renders them all the more valuable for close study.

Additional morphological and morphophonological data were also collected as part of the questionnaire by survey fieldworkers, but only the word list data have been included in the published volumes, in narrow transcription. Data for the present study were taken from these unpublished sources, held in the archives of the Linguistic Survey of Scotland, at Edinburgh University.

\section{B. Scottish Gaelic as an endangered language}

Scottish Gaelic, spoken primarily in the mountainous Highlands and western islands of Scotland, has been declining even in these areas since the earliest census data (cf. Mackinnon 1993; Withers 1984). The map indicating Gaelic speakers by county in the 
census results of 1891 (Withers 1984: 214) clearly illustrates the Highland line, demarcating the southern and eastern reaches of the Gaidhealtachd, or Gaelic-speaking region. Most recent census results are discouraging; as McLeod summarizes, "the language has continued to weaken...to the point where it now can hardly be said to function as a community language anywhere in Scotland" (McLeod 2006: 12). While the only significant figures of Gaelic speakers as a percentage of local communities are still to be found in the Western Isles, Skye, and the Highlands, still, more than $40 \%$ of all Gaelic speakers in Scotland live outside the Gaidhealtachd, in urban centers such as Glasgow, Edinburgh, and Aberdeen (General Register Office for Scotland, 2005, http://www.gro-scotland.gov.uk/files/gaelic-rep-english-commentary.pdf).

Figures one and two show the change in the demographic distribution of Gaelic speakers between 1951 (around the beginning of the Linguistic Survey of Scotland project) and the most recent census figures of 2001. Note in particular that nowadays (i.e. 2001), even the sparsely populated Western Isles have declined to less than $75 \%$ who self-report as being Gaelic-speaking, while the most populous town in the region, Stornoway, Lewis, only has $40-60 \%$ of its population as self-identified Gaelic speakers. Similarly, the Isle of Skye is now only 20-40\% Gaelic-speaking, while the area from the western highlands to the periphery of the Highland line is only $5 \%$ Gaelic speaking or less.

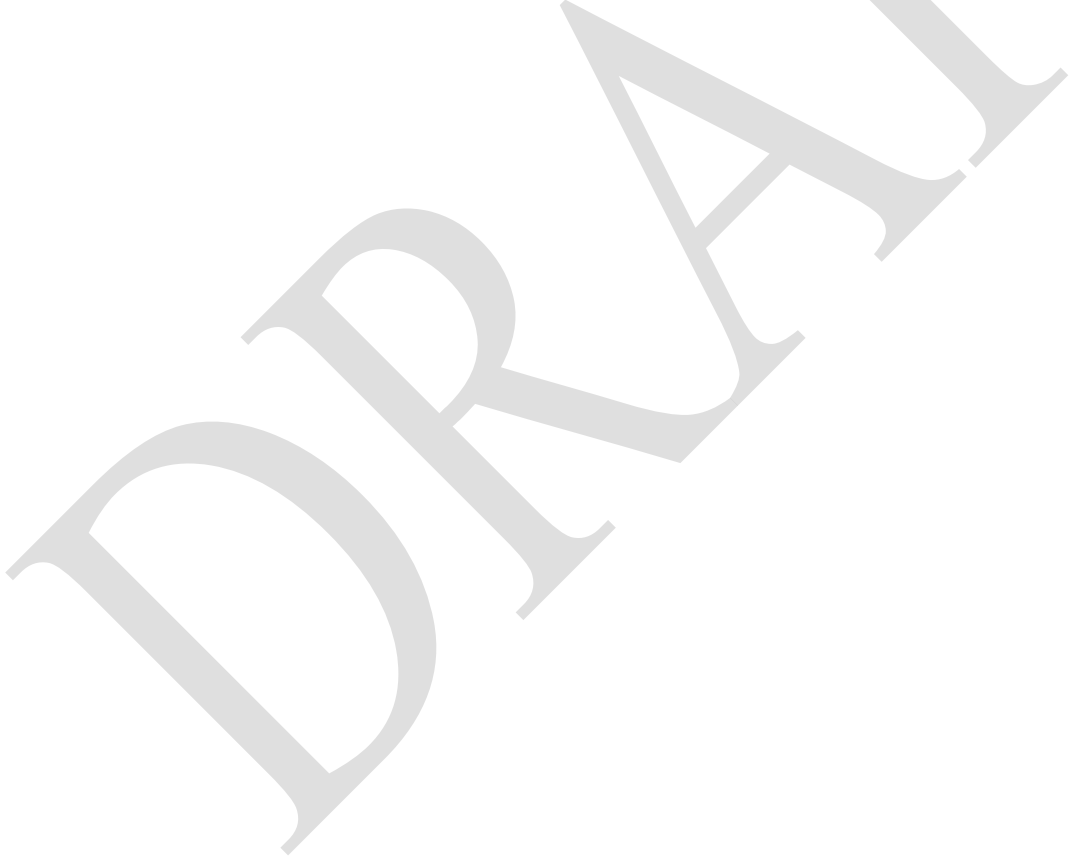


Figure 1: Gaelic speaking by parish, 1951 (from Withers, 1984: 232)

\section{Gaelic in Scotland 1698-1981}

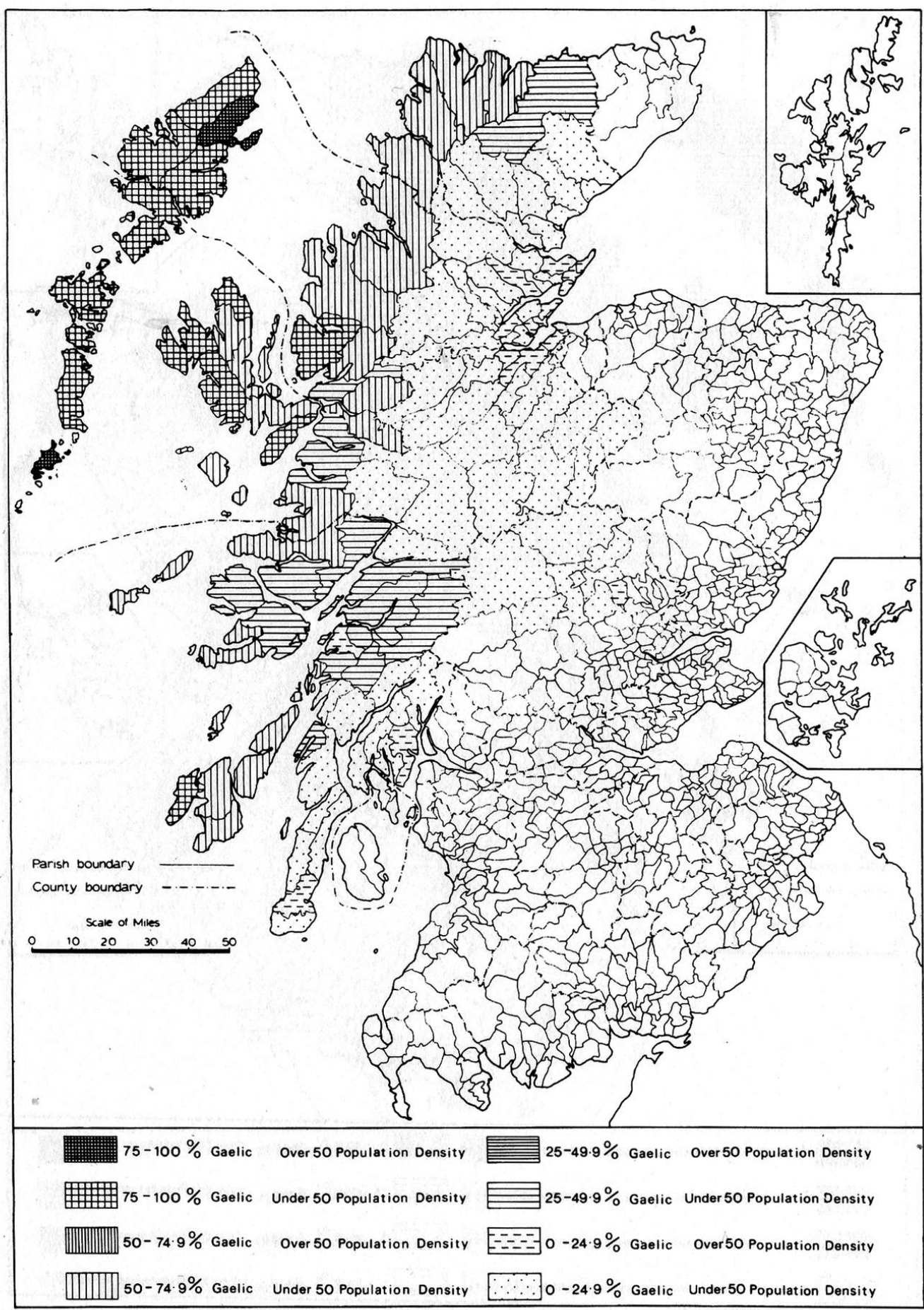

Fig. 67. Gaelic speaking by parish, 1951 
Figure 2: Parishes in Scotland by the percentage of people aged 3 and over who speak Gaelic, 2001 (source, Scotland's Census 2001 - Gaelic report; General Register Office for Scotland 2005)

Map 2 - Parishes in Scotland by the percentage of people aged 3 and over who speak Gaelic, 2001

$$
\begin{aligned}
& 00 \%-<0.5 \%
\end{aligned}
$$

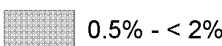

$$
\begin{aligned}
& 2 \%-<5 \% \\
& 5 \%-<20 \%
\end{aligned}
$$

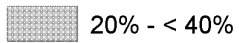

$$
\begin{aligned}
& 40 \%-<60 \% \\
& 60 \%-<75 \%
\end{aligned}
$$

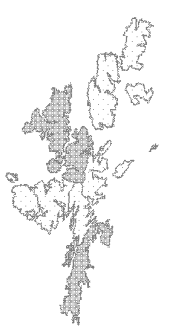


Further analysis of the 2001 census data by MacKinnon 2004 examines, with little optimism, the possibility of reversing language shift (cf. Fishman 1991) in Scotland, with a particularly close examination of intergenerational ratio (comparing numbers of speakers at different age grades) and intergenerational gain/loss (comparing census data from 1991 and 2001). Evaluating Gaelic along with other Celtic languages within the United Kingdom, MacKinnon concludes that while "Irish is fairly steadily maintained [in Northern Ireland]... Gaelic is in scarcely retarded free-fall and Welsh shows strong evidence of genuine recovery" (MacKinnon 2004:109).

While the total number of Gaelic speakers in Scotland, according to the 2001 census, was 58,652 , this represents a rapid decline even since 1951, when the census identified 95,447 Gaelic speakers (still not $2 \%$ of the total population at that time). The data collected for the Linguistic Survey of Scotland represents a valuable resource of transcribed material from across the Gaidhealtacht which Celticists and linguists can ill-afford to ignore; indeed, we have transcribed speech from some of the very last speakers and semispeakers of local varieties of Gaelic. For example, points 14, 15, and 16 of this survey represent the highly distinctive variety of Gaelic belonging to speakers born on the island of St. Kilda, whose 36 remaining residents were evacuated to mainland Scotland in 1930.

\section{C. Survey subjects}

As the Linguistic Survey of Scotland took shape in 1949-1950, the priorities and methodology of the survey in many ways reflect other linguistic atlas projects of that period (see Jackson 1958; Gillies 1988; and Bosch 2006 for more detailed discussions of the history and methodology of the survey). As with the roughly contemporaneous American survey projects (eg. Kurath at al. 1939-43 [LANE]; McDavid et al 1980, 198286 [LAMSAS]), and the similar project for Irish (Wagner 1958-69 [LASID]) the focus was placed primarily on the speech of a rural, relatively stable population. A glance at the Survey's geographical coverage will illustrate how successful Survey workers were in recording the very last "ideal" speakers in some regions. The project director, Kenneth Jackson, later described strict requirements for identifying survey respondents:

“...we pick our informants with very great care, making sure that they were themselves born and brought up in the immediate neighbourhood whose dialect we are studying, and that both their father and their mother were likewise. ...We try if possible also to avoid those who are married to speakers of other dialects, or have themselves lived for a very long time in another dialect area" (Jackson 1958: 232).

Although field researchers were expected to seek out the "best" representatives of local speech varieties, depending on the linguistic demographics of each area, semi-speakers as well as fluent conversationalists could serve as survey respondents, provided the individual's personal history satisfied the above requirements. Given population movement and individual histories, these "best" speakers cannot be assumed to be representative of their contemporaries, nor of younger speakers from their location. They do provide a reasonable representative system, given that their own experience of 
language input was relatively local for two generations before the survey. Brief paragraphs describing each respondent are included in volume 1 of the SGDS ("Chapter 5, Informants and locations").

\section{Eclipsis: The Nasal Mutation}

Like other Celtic languages, Scottish Gaelic demonstrates the phenomenon of initial consonant mutation, a morphosyntactic series of alternations which affect the initial consonants of words. The nasal mutation, known to celticists as eclipsis, historically applied following certain nasal consonants; synchronically the trigger is no longer purely phonological, nor is the result straightforwardly a phonetic nasalization. The most common example of the nasal mutation occurs when certain nouns are preceded by the definite article, which in standard orthography is an (or am before labials). Note that it is only masculine nominative nouns that select a form of the article which triggers this nasal mutation, and it does so only in some initial consonants. Feminine nominative nouns select a different form, orthographically $a^{\prime}$ (or an before dentals), which triggers a different mutation, lenition, which spirantizes or otherwise weakens certain initial consonants.

(1) Voiceless initial: [ $\left.\mathrm{k}^{\mathrm{h}} \mathrm{aht}\right]$ 'cat'

[əท ${ }^{g}$ haht] 'the cat' (with eclipsis) \{pt114; Skye

(2) Voiced initial: [bavl' $\left.{ }^{\mathrm{Y}}\right]$ 'limb'

[omavl $\left.{ }^{\mathrm{Y}}\right]^{\prime}$ 'the limb' (with eclipsis) $\{\mathrm{pt114}\}$

The actual presence of a vowel for the article is not obligatory: when the initial consonant of the noun is one that may demonstrate eclipsis, in some instances mutation may serve as the only evidence of the definite article. Oftedal describes this for the Gaelic of Leurbost (Lewis) thus: "Since the initial [ə] is caducous, the article is very often observable only in the initial of the noun. If this initial is not susceptible to mutations, the article is not observable at all in those positions where a caducous $ə$ is dropped..." (Oftedal 1956:201).

$$
\begin{array}{llll}
\text { Voiceless: } & \text { am poll 'the mud' } & {\left[\mathrm{mp}^{\mathrm{h}} \mathrm{Ju} \mathrm{l}^{\mathrm{Y}}\right]} & \{\mathrm{pt} 2 \text {; Lewis }\} \\
\text { Voiced: } & \text { am ball 'the limb' } & {\left[\mathrm{m}^{\mathrm{b}} \mathrm{avl}{ }^{\mathrm{Y}}\right]} & \{\mathrm{pt} 2\}
\end{array}
$$

Interestingly, from a phonologist's perspective, the nasal mutation affects word initial fortis (voiceless) and lenis (voiced) stops differently, usually triggering some nasalizing effect on voiced stops, while voicing the voiceless stops. Crucially also, the nasal mutation may create novel segments - such as an aspirated nasal-that are nonetheless contrastive at a surface level; a phonetic difference like [p] or [m] vs. [mh] is thus contrastive (as in 4), albeit the meaning difference is morphosyntactic rather than lexical, making this a "quasiphonemic" contrast (Scobbie and Stuart-Smith, in press). This raises interesting questions about whether this morphosyntactic and rather abstract mutation is "phonetic", in the sense that it gives rise to marked segments which are not strictly- 
speaking phonemic in Gaelic (and thus is not structure-preserving in the sense of Kiparsky), or whether it is "truly" phonological.

$$
\begin{aligned}
& \text { Aspirated nasal under eclipsis: \{pt3, Lewis\} } \\
& \text { Am poll 'the mud' } \quad\left[\mathrm{mhovl}^{\mathrm{P}}\right] \\
& \text { An tarbh 'the bull' [n }{ }^{\mathrm{B} h a r a ̀ v] ~} \\
& \text { An caolas 'the narrows' [yhu: }{ }^{\mathrm{Y}} \text { əs] }
\end{aligned}
$$

The examples in (4), (5), and (6) show rather different phonetic realizations of the eclipsis forms, which may be due to random variation of some kind (which is of little phonological interest) or may be representative of subtly-different targets for the eclipsis forms. Insofar as fine phonetic detail is arbitrarily speaker specific or dialectal, it is learned, and part of the grammar. Consideration of the variation between speakers can thus add to our knowledge of how specific the grammars of different languages must be. If the variation is structured in some way, then information about this variation will be

\begin{tabular}{|c|c|c|}
\hline Am post & 'the post' & {$\left[\mathrm{mb}^{\mathrm{f}} \mathrm{Jst}\right]$} \\
\hline An tarbh & 'the bull' & {$\left[\mathrm{nd}^{\mathrm{f}} \operatorname{ara}^{\mathrm{v}}\right]$} \\
\hline An cat & 'the cat' & {$\left[\mathrm{gg}^{\mathrm{h}} \mathrm{a}^{\mathrm{h}} \mathrm{t}\right]$} \\
\hline Am ball & 'the limb' & {$\left[\mathrm{mba}: 1^{\mathrm{Y}}\right]$} \\
\hline Nan daoine & 'of the men' & [nəndũ̃:n ${ }^{\mathrm{j}}$ \\
\hline An guth & 'the voice' & [ngu] \\
\hline
\end{tabular}
linguistically valuable. Given the data from the corpus, the most obvious structure we can look for is geographical variation.

(5) Aspirated vs. unaspirated 'voiced' stops under eclipsis: \{pt152, Easter Ross\}

Nasalization may also neutralize the contrast between voiced and voiceless radical (initial) consonants in certain speech varieties, as in (6). Neutralization of the feature /voice/ of initial stops in masculine definite forms seems a rather odd characteristic, and it would be interesting to see if there is any geographical and/or phonetic pattern to it. Is neutralization limited to just some variants of eclipsis, for example?

(6) Absence of nasal segment under eclipsis: \{pt142, East Sutherland $\}$

$\begin{array}{lll}\text { Am post } & \text { 'the post' } & \text { [ə bost] } \\ \text { An tarbh } & \text { 'the bull' } & \text { [ə darv] } \\ \text { An cat } & \text { 'the cat' } & \text { [ə gat] } \\ \text { Am ball } & \text { 'the limb' } & \text { (not recorded) } \\ \text { Nan daoine } & \text { 'of the men' } & \left.\text { [nə dũ: } n^{j}\right] \\ \text { An gob } & \text { 'the beak' } & \text { [ə gob] }\end{array}$

III. A. Survey data on eclipsis

Somewhat less than two pages (pp36 \& 37) of the original 48-page survey are devoted to gathering evidence of eclipsis; an example of page 36 is provided below. The 
questionnaire asks for evidence of eclipsis in masculine nouns preceded by the definite article an/am. Page 37 asks whether the possessives 'our' ar and 'your' bhur 'eclipse vowels [with /n/], or [add a] prefix h" before vowel-initial nouns (e.g. ar $n$-athair or ar $h$ athair for 'our father'). In order to focus on the expression of eclipsis in voiced and voiceless stops, and the geographic distribution of its neutralization, we looked only at the data found on page 36 of the survey instrument: that is, evidence of the nasal mutation of masculine nouns beginning with voiced or voiceless stops. At this stage in our analysis we are not able to consider the dialect variation in (a) other possible triggers of eclipsis, or (b) how or whether eclipsis is expressed in the cases of initial fricatives [ $\mathrm{f}$ s $\left.\int\right]$, or initial vowels.

Our task is further complicated by the factors of fieldworker variation (which will be discussed below) and the changing nature of transcription practices over the course of this long-term project. In his detailed exposition of the transcription principles of the Survey project, O’ Dochartaigh points out that Jackson did not initially insist on transcribing initial postaspiration; that is, the aspiration found word-initially which forms the basis of the fortis/lenis contrast in many varieties of Gaelic. O'Dochartaigh quotes Jackson commenting late in the project that "the voiceless stops are aspirate [sic] initially, and should be written $\left[\mathrm{p}^{\mathrm{h}}\right],\left[\mathrm{t}^{\mathrm{h}}\right]$, etc." although apparently they were not uniformly so indicated (KHJ 1963, qtd. in O'Dochartaigh 1997:134). For example we find that postaspiration is not normally recorded by fieldworker Fred MacAulay, who worked primarily in eastern and southern regions; so here again we cannot know for sure whether the lack of postaspiration in certain areas - especially peripheral areas - is due to differing transcription practices, or genuine differences in pronunciation. Editorial steps were taken by Jackson to ameliorate the confound between inter-fieldworker variation and geographical variation among speakers, through his oversight of all the data.

Figure 3 shows page 36 of the Fair Copy of the questionnaire for the Skye III district; fair copies were frequently copied by Jackson from the actual fieldnotes, and generally include marginalia by Jackson (signed K.J.) and occasionally also those of the original fieldworker, though it is impossible to know what notes may have been lost from the original working copies. As the Figure demonstrates, it was Jackson's habit to copy several speakers from a single region into parallel columns of a single Fair Copy; this leads to a somewhat tangled page, especially when diacritics and footnotes are taken into account. Each column represents data collected from a single speaker, identified by speaker's initial(s) and two numbers: one from a point-numbering system developed by Jackson, and a second from a later numbering system employed for the published SGDS. The transcription system is based on the International Phonetic Alphabet as revised by traditional practice within celtic studies (see Hamp 1988 for a discussion of transcription usage in the Survey). ${ }^{\text {ii }}$ 
Figure 3: Gaelic questionnaire p. 36: Eclipsis.

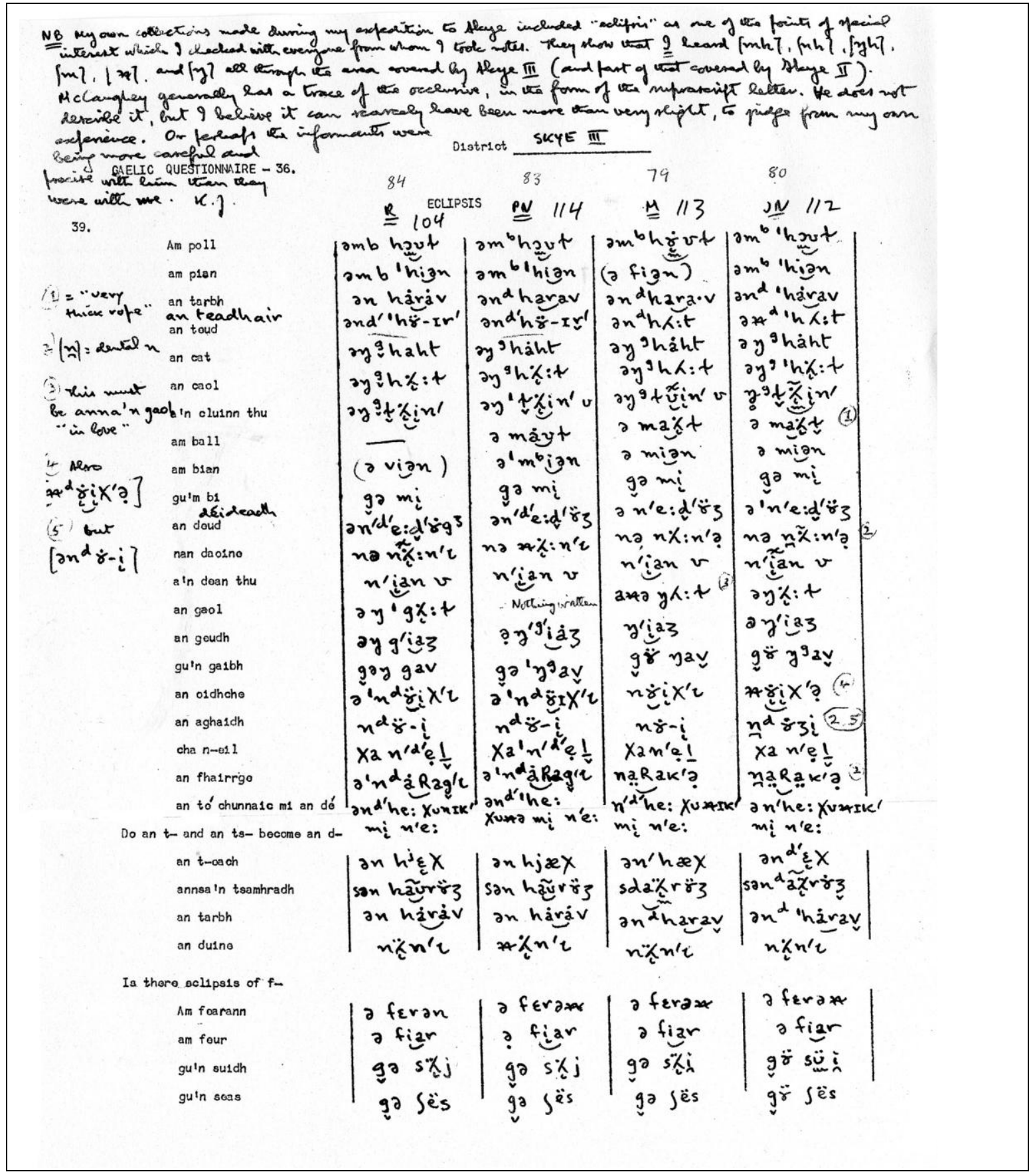

[District: Skye III; points 104, 114, 113, 112; Fieldworker: Terrence McCaughey; Fair Copy by Kenneth H. Jackson] Courtesy of the archives of the Linguistic Survey of Scotland, Gaelic and Scottish Studies, Edinburgh University. 


\section{B. Surface phonetic variation}

The Survey data show a surprising amount of phonetic variation in how the eclipsis context (e.g. /am\#b/ or /am\#p/) is pronounced. We collated this variation and present it in Table 1 below, using word-initial bilabial stops as exemplars for all places of articulation (e.g. /am\#b/ or /am\#p/). (We have no reason to assume at this stage that places of articulation vary in how eclipsis operates.) We tabulate this variation, below, from a purely phonetic perspective in two dimensions: an unaspirated/aspirated dimension and a structural oral-nasal dimension.

In the following table, only eclipsis forms are presented. In addition, basic citation forms would be simple C, namely [p] from /b/ (and sometimes from $/ \mathrm{p} /$ ) and [ $\left.\mathrm{p}^{\mathrm{h}}\right]$ from $/ \mathrm{p} /$. Horizontal rows illustrate the range of forms of the consonant (sequence) appearing at the start of the noun, plus potentially its nasalization and/or voicing due to eclipsis as follows: $\mathrm{N}=$ a plain nasal, $\mathrm{NC}=$ a nasal+stop cluster, ${ }^{\mathrm{N}} \mathrm{C}=$ a prenasalized stop and $\mathrm{C}=\mathrm{a}$ plain stop, without nasal. In other words, the putative sequence $/ \mathrm{m \# C/} \mathrm{can} \mathrm{be} \mathrm{a} \mathrm{cluster,} \mathrm{or}$ the sequence can be reduced to a singleton nasal, or a singleton oral, consonant. The left side column shows unaspirated variants (which generally arise in the context of nouninitial /b/), while the right column illustrates forms which are aspirated (always due to the noun starting in $/ \mathrm{p} /$ ). Aspirated nasals and stops tend to be transcribed as voiceless or devoiced, although this is not consistent nor necessary.

Table 1: Range of transcribed variation in initial stops with nasal mutation

\begin{tabular}{|c|c|c|}
\hline & Unaspirated & Aspirated \\
\hline $\mathrm{N}$ & $\mathrm{m}$ & $\mathrm{m}^{\mathrm{h}} \mathrm{mh} \mathrm{m}_{\mathrm{o}}^{\mathrm{h}}$ \\
\hline $\mathrm{NC}$ & $\begin{array}{ll}\mathrm{mb} & \mathrm{mb}_{0} \mathrm{mb} \\
\mathrm{mb} & \end{array}$ & $\begin{array}{lllll}m b h & m_{o} b^{h} & m b^{h} & m b h & m b^{h} \\
m p^{h} & m^{p} h & m b h & m^{b} h & m^{b}{ }^{b} h\end{array}$ \\
\hline${ }^{\mathrm{N}} \mathrm{C}$ & $\begin{array}{lll}\mathrm{m}_{\mathrm{b}} & \mathrm{m}_{\mathrm{p}} & \mathrm{m}_{\mathrm{o}} \mathrm{b}\end{array}$ & $\mathrm{m}_{0}^{\mathrm{h}} \quad \mathrm{m}_{\mathrm{b}^{\mathrm{h}}}^{\mathrm{h}}$ \\
\hline $\mathrm{C}$ & $\mathrm{b}$ & $\mathrm{b}^{\mathrm{h}}$ \\
\hline
\end{tabular}

Not examined here is a third dimension, namely whether the initial schwa of the definite article is phonetically realised or not. It can be omitted in all types apart from those beginning with non-nasalized $\left[\mathrm{b}^{\mathrm{h}}\right]$.

Underlying voiced stops are invariably realized with one of the alternatives from the left "unaspirated" column; they are never aspirated. Underlying voiceless stops however are considerably more variable: in the eclipsis context they may retain aspiration, as represented in the right-hand column, or they may lose it. However, even if aspiration is lost, the contrast between voiced and voiceless (unaspirated vs. aspirated) need not be neutralized; instead the contrast may be coded in the presence or absence of the oral stop or of the nasal itself. (See maps below). 
The variation in transcription illustrated above may be surprising to those who have not worked with this type of transcribed survey data. While we expect fine-grained noncategorical variation in acoustic data, we have perhaps grown to expect categorical or near-categorical certainty in phonetic transcription, even when we are talking about surface variation (e.g. in the oft-cited example from English, the /p/ is either aspirated, in 'pit', or unaspirated, in 'spit'). It is something of an eye-opener to see the transcriptions offered here, where the reader is required to interpret the difference between a raised stop and a stop 'on the line'; or distinguish between voiced [b], [b] with the devoicing diacritic, devoiced and aspirated [bh], or unaspirated [p]. To their credit, the fieldworkers on this project were making a genuine effort to record the minute details which might, under comparison with the whole, provide evidence of regional variation, either phonetic or phonological. (In fact they were primarily concerned with phonetic distinctions, rather than phonological ones, as evidence from the archives and Jackson's correspondence suggests).

One of the challenges of working with this set of data is to identify which aspects of fine phonetic detail are simply evidence of "fieldworker's isoglosses;" after all, eight fieldworkers contributed to the survey's collection. For practical reasons, fieldworkers tended to work in specific geographic areas, so the confound between genuine geographic variation and the "fieldworker's isogloss" may ultimately remain unanswerable. However, mapping these phonetic factors can provide visual confirmation of regional trend and local specificity, which in the long run significantly aid our understanding of the geographical distribution of these several parameters.

As an example of our interpretive dilemma, consider the lengthy marginal commentary by Kenneth Jackson on the questionnaire page (provided), which reads as follows:

"NB My own collections made during my expedition to Skye included "eclipsis" as one of the points of special interest which I checked with everyone from whom I took notes. They show that I heard [mh], [nh], $[\mathrm{yh}],[\mathrm{m}],\left[\mathrm{n}^{\mathrm{\gamma}}\right]$, and $[\mathrm{y}]$ all through the area covered by Skye III (and part of that covered by Skye II). McCaughey generally has a trace of the occlusive, in the form of the suprascript letter. He does not describe it, but I believe it can scarcely have been more than very slight, to judge from my own experience. Or perhaps the informants were being more careful and precise with him than they were with me. K.J." (Jackson, Fair copy Skye III p. 36, survey archives, emphasis in the original).

That is, in his own work in this same region Jackson heard and noted a contrast between aspirated nasal segments (representing the aspirated oral stops in the nasalization context), as contrasted with full but unaspirated nasals (the unaspirated or voiced stop counterparts), while the fieldworker TMC in this region notes a slight, superscript oral occlusion preceding the nasal in the case of the aspirated series. In fact, from the evidence provided in Figure 3, the fieldworker TMC is quite consistent in noting some evidence of the occlusive, either as superscript or (for point 104) as a full obstruent. As 
Jackson notes, the distinction could result from careful speech in the one case, but we cannot know for certain.

While the question of fieldworker variation remains a thorny one, then, a map or other graphic display of variation can at a minimum provide a "first pass" analysis to determine which diacritic details demonstrate regular and specific geographic distribution, and which instances appear more randomly distributed.

Additional insight comes from taking a phonetic perspective to interpret these fine distinctions. While the distinction between $\left[\mathrm{mp}^{\mathrm{h}}\right]$ and $\left[\mathrm{m}^{\mathrm{p}} \mathrm{h}\right]$, for example, appears overly detailed and probably trivial, and that between $[\mathrm{m}]$ and $[\mathrm{mb}]$ seems apparently larger and probably more meaningful, in fact these differences may be differences of degree rather than of kind. Given data from just a couple of speakers, it would not be possible to make such a claim, but we have the advantage of being able to view these variations in the context of a gradient phonetic cline from $\mathrm{N}$ to $\mathrm{C}$ across more than two hundred speakers.

From a phonetic perspective the presence or absence of a "segment" in the eclipsis forms can be modeled through differences in gestural overlap (Browman and Goldstein 1990, 1992). In this view, a slight variation in the alignment of articulations can result in either a subtle transcriptional difference, such as increased duration of nasality or aspiration; an intermediate difference, such as a short $\left(\left[\mathrm{m}^{\mathrm{p}}\right]\right)$ or long $([\mathrm{mp}])$ oral phase in a cluster; or an apparently more radical difference, such as the presence vs. absence of a segment altogether.

The difference between N, NC and C forms in Table 1 could perhaps be due to such differences in gestural alignment, but what really matters is whether they are systematic, and learned. If so, the survey might reveal this through a geographically-distributed set of isoglosses. Similarly, the difference between strongly and weakly aspirated forms, and the devoicing of the stop and nasal consonant can be explored from this perspective.

\section{Geographical distribution of the nasal mutation}

Below we provide two maps which do not yet implement the complexity of the parametric scales of nasalization or voicing, nor deal overtly with fieldworker variation in the fieldnotes. However they do show clusterings of phenomena, and where those clusters are located. 
Figure 4: Neutralization of voicing and distribution of voiceless and voiced aspiration in eclipsis.

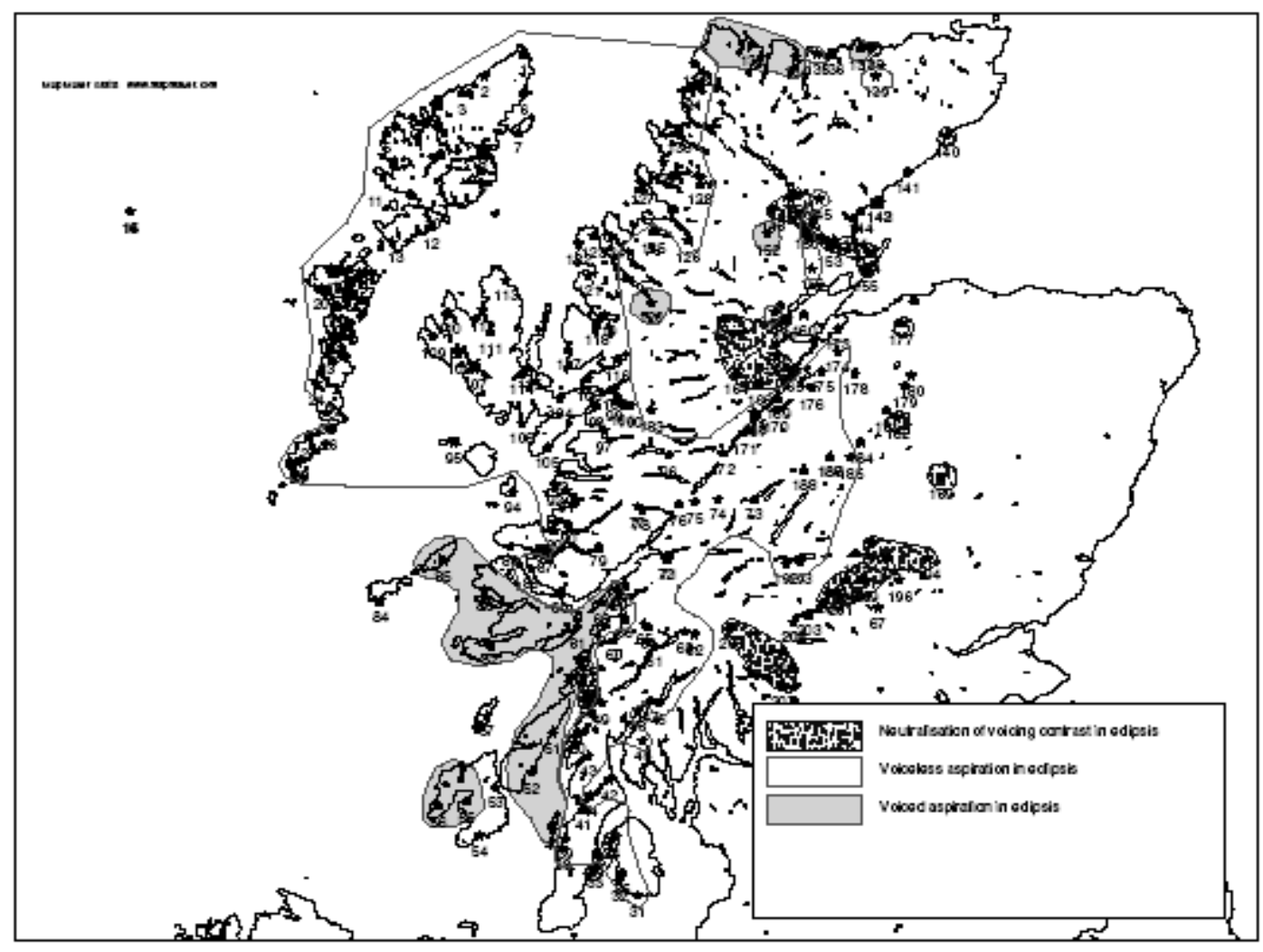


Figure 4 shows the distribution of areas where (a) the voicing contrast is neutralized under eclipsis (spotted), and (b) aspiration is maintained (both plain and shaded areas) for voiceless and/or aspirated initial consonants. The largest outlined area shows the distribution of voiceless aspiration (in all instances only underlying voiceless stops are ever aspirated). In addition, then, the sum of all outlined and shaded areas demonstrates where the fortis (aspirated) and lenis (unaspirated) initial consonants remain contrastive in the context of the nasal mutation. To abstract away from detail, in these areas we see an initial /p/ expressed as some variant of [mbh] after nasalization, whereas the initial /b/ is expressed as $[\mathrm{mb}]$. The contrast remains one primarily of aspiration.

However, a smaller area to the southwest, encompassing Coll, Mull, Jura, and parts of Islay, as well as a few northern points $(133,134,137)$ illustrate a voiced variant of aspiration, shown as shaded. Here, an initial voiceless aspirated stop, when in the context of the nasal mutation, becomes voiced - and that voicing appears to continue through the expression of aspiration. Thus the nasalization of $/ \mathrm{p} /$ results in [mbf] or similar.

It may be worthwhile to note that one fieldworker was responsible for all the (shaded) voiced aspiration data, including the non-contiguous northern points. In fact we have chosen to map this contrast primarily as an exercise to illustrate the likely phenomenon of fieldworker variation: although the transcription is consistent (and we have no reason to question its accuracy), we cannot be certain that these are the only areas that display a voiced aspiration in the context of the nasal mutation. We are somewhat hampered in developing this hypothesis by the lack of detailed regionally-specific monographs exploring any of these particular areas; there are no detailed phonological studies of North Sutherland, Mull, Islay, or Jura such as already exist for East Perthshire, East Sutherland, Barra, or Lewis, for example, so we have no independent confirmation of these data. We hypothesize that the phonetic difference between the pronunciations expressed here regarding the "quality" of aspiration (voiced or voiceless) remains a lowlevel phonetic process of which most speakers and (probably) listeners remain unaware.

Also identified on this map are spotted areas dotted along the east in which underlying voiced and voiceless stops are in fact merged in eclipsis (e.g. am poll $=\underline{\text { am ball }}$. These areas include East Sutherland (cf. Dorian 1978), parts of Easter Ross and Speyside, and Perthshire (both North West and East); see also examples provided in (6) above. These areas generally do not coincide with aspiration, or show only minimal aspiration in the fortis-lenis contrast. Thus, in most of these eastern points the primary feature distinguishing fortis from lenis initial stop consonants (transcribed predominantly as a distinction in voicing) is neutralized in the environment of the nasal mutation. This corresponds to evidence provided in Ó Murchú's 1989 study of East Perthshire Gaelic, which draws heavily on data from the archives of the linguistic survey. In ordinary wordinitial position, Ó Murchú describes the initial stop consonants /p t k/ (etc.) as "voiceless postaspirate stops" (1989: 102), although "postaspiration is not very marked by general Scots Gaelic standards" (102). The lenis initials /b d g/ (etc) are described as "voiceless ( sic) nonaspirate (lax) stops" (102). In a following section on prenasalization, while the term 'neutralization' is not mentioned, it is clear from Ó Murchú's discussion that the 
nasal-stop context eliminates the original word-initial contrast in stops: examples are provided as follows:

(7) Neutralization of the initial contrast of [voice] under eclipsis:

\begin{tabular}{|c|c|}
\hline am pùd & [mbuid] \\
\hline am baile & [mbal] \\
\hline an toll & {$\left[\operatorname{ndol}^{\mathrm{Y}}:\right]$} \\
\hline an dorus & [ndors] \\
\hline
\end{tabular}

From Figures 4 and 5 (below) we see then that neutralization of the initial contrast in the stop consonant system tends to be found in peripheral areas on the east and south of the Gaidhealtachd. It is also worth mentioning that fieldwork on the points encompassed by these spotty areas (approximately points 138 through 207) was accomplished by seven out of the eight original fieldworkers. Thus we cannot point to fieldworker transcription practice to account for the occurrence of contrast-neutralization in these varied and geographically-dispersed areas. The shared factor for "neutralizing areas" remains only the peripheral nature of these locations, and the scarcity of Gaelic speakers in these combined regions, generally less than 5\%). The neutralization of this salient contrast may therefore represent (or result from?) language attrition in a context where Gaelic is little used. 
Figure 5. The distribution of the neutralization of the voicing contrast in eclipsis compared to the extremes of the structural oral-nasal dimension.

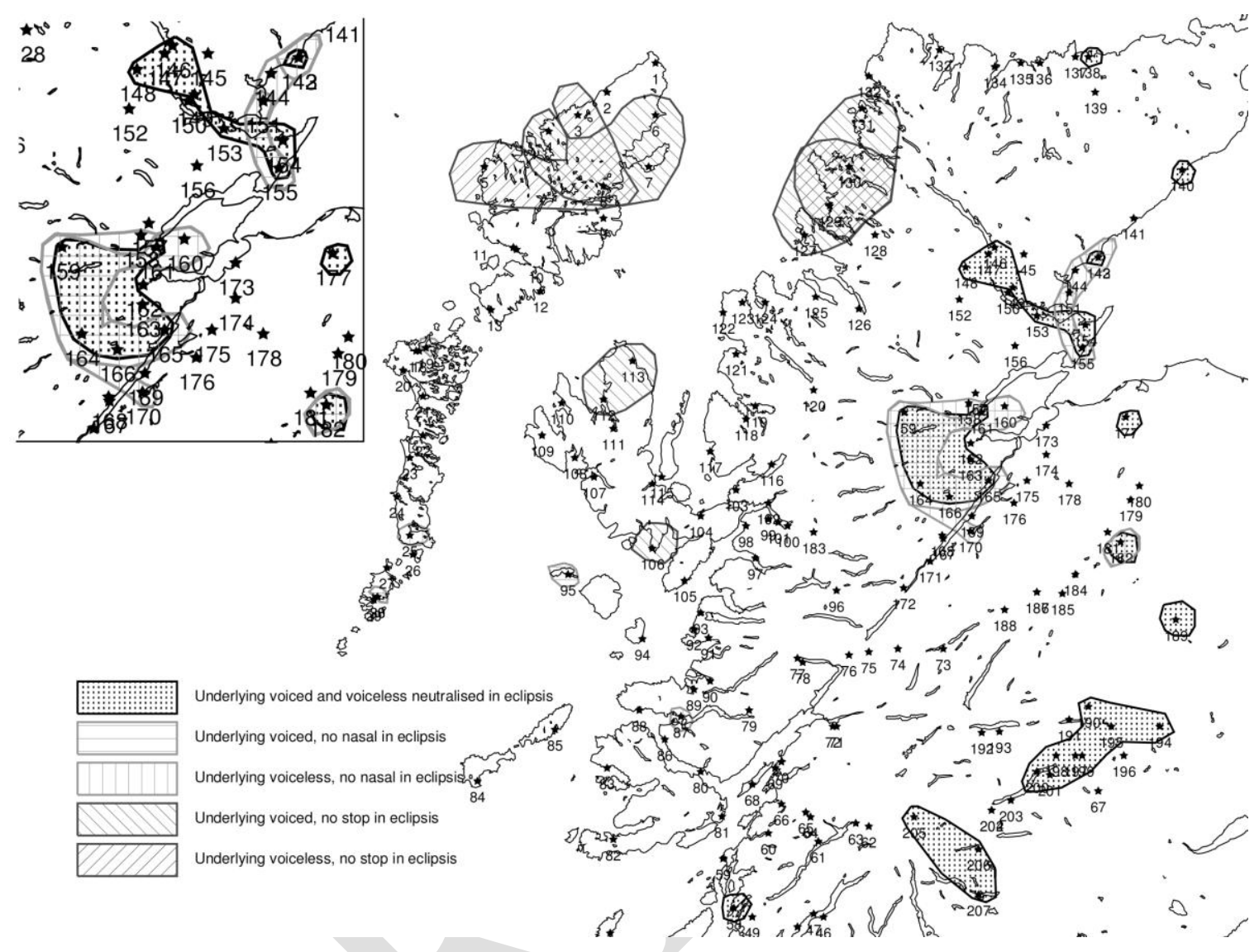


This Figure maps the distribution of neutralization of voicing contrast in eclipsis, in dotted areas, (as discussed above for Figure 4), as well as the distribution of two types of reduced cluster, which represent the two "extremes" of the oral-nasal dimension. In the first type of reduced cluster (a), mainly found in small dispersed areas to the east, shown in vertical or horizontal cross-hatching, the nasal can be lost (which overlaps with neutralization). Although the omission of the nasal is not exemplified in the East Perthshire data available on the survey instrument, in fact Ó Murchú claims the nasal element of the nasal mutation is commonly omitted "in highly frequent forms" (189:115), presumably as an optional phenomenon. Indeed he provides an example of this nasal deletion which conveniently also demonstrates the neutralization of the voiced/voiceless (or aspirated/unaspirated) distinction in the context of the nasal mutation:

$$
\text { /bals/ for /mbals/ am pailteas (Ó Murchú 189: 115) }
$$

So the omission of the nasal from the nasal mutation itself appears not to be constrained by the possibility of eliminating useful meaningful contrasts. Again, however, we note that these areas (in vertical or horizontal hatching on the map) overlap with neutralization only in the peripheral eastern areas, where spoken Gaelic has long been in decline; see inset.

In parts of Lewis and the northwest highlands, however, we find another "extreme" type of example: here, indicated by diagonal cross-hatching, (b) the stop itself can be lost; this type of cluster reduction never seems to co-occur with the neutralization of contrasts. This results in a typically Lewis Gaelic shibboleth, in which the stop under nasalization is represented as a nasal or aspirated nasal consonant word-initially. Thus, initial /p/ after the nasal mutation is pronounced as some variant of $[\mathrm{mh}]$, while $/ \mathrm{b} / \mathrm{is}$ simply $[\mathrm{m}]$. This was described by Borgstrøm in his 1940 comparative study, Dialects of the Outer Hebrides (cf. Borgstrøm 1940: 23), and reconfirmed by Oftedal's 1956 description of Leurbost Gaelic. The absence of the oral stop under eclipsis is widely understood by Gaelic speakers today to be indicative of Lewis speech (and may on occasion be employed to comic effect).

The contrasts illustrated in the map in Figure 5, then, show (a) where the nasal is omitted (vertical/horizontal hatching) and (b) where the oral stop is omitted (diagonal hatching). The regions geographically are not at opposite ends of the Gaelic speaking region, and future research is needed to see if there are any complex patterns of partial denasalization and partial de-oralization. The voiced and voiceless stops tend to pattern together in cluster reduction; for example, where the oral stop itself is lost, the contrast voiced/voiceless (or aspirated/ unaspirated) is nonetheless retained. Comparison of the two maps reveals that the area with aspirated nasals has no neutralization: the contrast is maintained as plain vs. aspirated nasal. (The aspirated nasals may themselves be devoiced to some extent.)

It is clear from the geographic distribution of the different variants of eclipsis forms that speakers specify the relative timing of at least three dimensions, but perhaps the result is not much different than one might predict from a segmental description in which the 
nasal or the oral stop was deleted. We lack the finer-grained phonetic data, especially instrumental data, that could investigate just how detailed these systems are.

What is interesting here is that the apparent $\mathrm{N}$ to $\mathrm{NC}$ to $\mathrm{C}$ cline is not represented as an evenly-spaced transition on the ground, geographically. While stop deletion is found in the far north of the Gaidhealtachd, nasal deletion appears to extend west-to-east just to the south, in a series of relatively isolated locations, with a cluster realization being more widespread.

Theoretically-speaking, instead of incorporating numerical targets into the grammar, more schematic formalizations of subtle differences in gestural alignment have been undertaken in Articulatory Phonology itself, and in gestural Optimality Theory (e.g. Gafos 2002, Bradley 2005). There seems to be an increasing acceptance that phonetically fine-grained specifications have to be represented in the grammar somehow. Evidence for or against such theories is not generally available in the phonological literature, because the broad segmental transcriptions found there beg the question. Cross-linguistic studies provide some support, particularly if dialects are included in the comparison, and if instrumental phonetic data are included. For example, see studies on geographical variation in intonation in Irish Gaelic (Dalton and Ni Chasaide, to appear) or consonantconsonant overlap in /kl/ clusters across Europe (Gibbon, Hardcastle and Nicolaidis, 1993) which show clines of alignment variation. The distribution of oral-nasal variation as presented here based on finely-transcribed survey data provides appropriate evidence both because of the large number of speakers, and by virtue of the fact that the data are structured, not because the data are simply phonetically subtle. Instrumental phonetic data from structured pools of subjects would be even more powerful evidence, and would be able to address the question of just how fine-grained grammars have to be.

\section{Significance of the study}

The detailed transcriptions of the Linguistic Survey archives offer a wealth of nearly unexamined data on geographic variation in Gaelic. Our focus here is to outline the bases for geographical or regional variation in the initial nasal mutation, in part because we saw so much transcribed variation in a casual review of the data, and in part because the nasal mutation seems to create novel and contrastive segments such as the initial voiceless aspirated nasal, which has important theoretical implications. However, because there is very little instrumental (articulatory or acoustic) data on this aspect of Scottish Gaelic phonology (although cf. Ladefoged 1998), at this early stage we simply don't know what aspects of the transcribed data are significant, and what elements are simply "noise," for example, due merely to fast-speech or careful speech phenomena, or individual idiosyncrasy. There are obvious and familiar lessons too for fieldwork on endangered languages, where large numbers of dialectally-variable speakers are unlikely to be available. First, transcriber bias can occur, undetected. Second, the system may have become attrited as the communities of use fail. Third, the fine phonetic variation between geographical or even socially-determined dialects will not be recoverable. When only small numbers of speakers are available, the best we can do is to record fine phonetic 
detail as accurately as possible, preferably instrumentally, and not force the phonological system into familiar and convenient categories.

Scottish Gaelic today is an endangered language, spoken by less than $2 \%$ of the population of Scotland. As can be seen by the figures cited, the geographic distribution of significant Gaelic-speaking population has shrunk dramatically since 1951. In addition, Gaelic today provides fertile ground for the examination of language-contact and language-change phenomena, although little work is being done in this area. Currently there is significant interest in developing a second large-scale geographic survey of Scottish linguistic practice, encompassing use of Gaelic, Scots, Doric, and other non-majority language practices. However, before a convincing argument can be made for financial support of such a project, it must be evident that previous survey efforts have been put to good use. This project represents one attempt to employ the detailed phonetic transcriptions of the survey to further our understanding of the geographic distribution of one phonological feature of Scottish Gaelic.

Authors' note: We would like to dedicate this paper to one particular informant contributing to the Linguistic Survey of Scotland, Duncan Black from Lismore (point 68), Scobbie's maternal grandfather.

\section{Works Cited}

Borgstrøm, C.H. 1937. The Dialect of Barra in the Outer Hebrides. Norsk Tidsskrift for Sprogvidenskap 8. Oslo: Aschehoug \& co.

Borgstrøm, C.H. 1940. The Dialects of the Outer Hebrides. Norsk Tidsskrift for Sprogvidenskap, suppl. bind I. Oslo: Aschehoug \& co.

Bradley, Travis G. 2005. Systematic markedness and phonetic detail in phonology. In Randall Gess and Ed Rubin (eds.) Experimental and Theoretical Approaches to Romance Linguistics. Amsterdam: John Benjamins, 41-62.

Browman, C. P. \& L. Goldstein 1990. Tiers in articulatory phonology, with some implications for casual speech. In J. Kingston \& M. E. Beckman (eds.) Papers in laboratory phonology I: between the grammar and physics of speech. Cambridge: Cambridge University Press. 341-376.

Browman, C. P. \& L. Goldstein 1992. Articulatory Phonology: an overview. Phonetica 49: $155-180$.

Dalton, Martha and Ailbhe Ní Chasaide (to appear). Alignment and Micro-Dialect Variation in Connaught Irish. To appear in Carlos Gussenhoven, C. \& Tomas Riad (eds.) Tone and Intonation in Europe. Mouton de Gruyter, Berlin .

Dorian, N. 1978. East Sutherland Gaelic. Dublin: Dublin Institute of Advanced Studies.

Fishman, J. 1991. Reversing Language Shift: Theoretical and Empirical Foundations of Assistance to Threatened Languages. Clevedon: Multilingual Matters.

Gafos, Adamantios. 2002. A Grammar of Gestural Coordination. Natural Language and Linguistic Theory 20.269-337.

Gibbon F., Hardcastle, W.J. and Nicolaidis, K. (1993) "Temporal and spatial aspects of lingual coarticulation in $/ \mathrm{kl} /$ sequences: a cross-linguistic investigation" Language and Speech, 36: 261-278. 
Gillies, William. 1988. The Atlas of Gaelic dialects: an interim report. Scottish Gaelic Studies 15: 1-5.

Hamp, Eric P. 1988. On the representation of Scottish Gaelic dialect phonetics. Scottish Gaelic Studies 15: 6-19.

Jackson, Kenneth H. 1958. The Situation of the Scottish Gaelic language, and the work of the Linguistic Survey of Scotland. Lochlann 1: 229-234.

Kurath, Hans et al. 1939-43. Linguistic Atlas of New England. Providence: ACLS. [LANE]

Ladefoged, Peter et al. 1998. Phonetic structures of Scottish Gaelic. UCLA ms. 43pp.

McDavid, Raven, et al. 1980, 1982-86. Linguistic Atlas of the Middle and South Atlantic States. Chicago, IL. [LAMSAS]

MacKinnon, Kenneth. 1993. 'Scottish Gaelic Today: Social History and Contemporary Status', in The Celtic Languages, ed. by Martin Ball, 491-535. London: Routledge.

MacKinnon, Kenneth. 2004. Reversing language shift: Celtic languages today-any evidence? Journal of Celtic Linguistics 8: 109-32.

McLeod, Wilson. 2006ms. Gaelic in contemporary Scotland: contradictions, challenges and strategies. Research report available at www.arts.ed.ac.uk/celtic/poileasaidh/.

Ó Dochartaigh, Cathair (ed.). 1994-97. Survey of the Gaelic Dialects of Scotland, 5 vols. [SGDS]. Dublin: Dublin Institute for Advanced Studies.

Ó Dochartaigh, Cathar. 1996. Two loans in Scottish Gaelic. Scottish Gaelic Studies 17: 305-313.

Oftedal, Magne. 1956. The Gaelic of Leurbost, Isle of Lewis. Norsk Tidsskrift for Sprogvidenskap, suppl. bind IV. Oslo: Aschehoug \& co.

Ó Maolalaigh, Roibeard. 1999. Transition zones, hyperdialectisms and historical change. Scottish Gaelic Studies 19: 195-233.

Ó Murchú, Máirtín.1985. Devoicing and preaspiration in varieties of Scottish Gaelic. Ériu 36: 195-198.

Scobbie, J.M and Stuart-Smith, J. [in press] Quasi-phonemic contrast and the fuzzy inventory: examples from Scottish English. In Contrast: Perception and Acquisition: Selected papers from the Second International Conference on Contrast in Phonology, ed. by Peter Avery, Elan B. Dresher and Keren Rice. Toronto: Mouton de Gruyter/University of Toronto.

Scotland's Census Reports On-Line [SCROL], www.scrol.gov.uk/scrol/common/home.jsp

Scotland's Census 2001 - Gaelic report, www.groscotland.gov.uk/statistics/census/censushm/scotcen/scotcen2/scotcengaelic/index.html

Ternes, Elmar. 1973. The phonemic analysis of Scottish Gaelic, based on the dialect of Applecross, Ross-shire. Hamburg: Helmut Buske Verlag.

Viereck, Wolfgang. 1991 \& 1997. (In collaboration with Heinrich Ramisch). The computer developed linguistic atlas of England, vols. 1 \& 2. Computational producton: Harald Händler et al. Tübingen: Niemeyer.

Wagner, Heinrich. 1958-69. Linguistic atlas and survey of Irish dialects. Dublin. [LASID] 
Withers, Charles. 1984. Gaelic in Scotland, 1698-1981: The geographical history of a language. Edinburgh: John Donald Publishers.

\footnotetext{
i Acknowledgements: Many thanks to the department of Celtic and Scottish Studies, Edinburgh University, for access to the archives of the Linguistic Survey of Scotland. This research was supported in part by sabbatical fellowships from the American Philosophical Society and the Institute for Advanced Study in the Humanities, Edinburgh University, granted to Anna Bosch, and most gratefully acknowledged.

ii Jackson's transcription practice was modified, as described in Hamp 1988, for the publication of the SGDS volumes in 1994; phonetic transcription in the present essay is additionally modified so as to conform as closely as possible to the current (2005) approved version of the International Phonetic Alphabet. Notably, therefore, palatalized consonants are written with the superscript $\left[{ }^{j}\right]$ in this text, rather than an apostrophe; velarized consonants are transcribed here with a superscript gamma $\left[{ }^{\mathrm{V}}\right]$, rather than a bisecting tilde as was Jackson's practice.
} 